\title{
Influence of Occupational Noise Exposure on Cognitive Ability of Grinders
}

\author{
Wei Qu1, Hua Shao', Hong Zhang1, Jihu Yi², Aihua Song ${ }^{3}$, Yongle Shan ${ }^{*}$, Rui Wang1* \\ ${ }^{1}$ Shandong Academy of Occupational Health and Occupational Medicine, Jinan, China \\ ${ }^{2}$ Shandong Academy of Medical Science, Jinan, China \\ ${ }^{3}$ Tianqiao District Environmental Protection Bureau, Jinan, China \\ Email: "shanyongle@163.com, ${ }^{*} 13075308745 @ 163 . c o m$
}

Received 22 June 2016; accepted 23 August 2016; published 26 August 2016

Copyright (C) 2016 by authors and Scientific Research Publishing Inc.

This work is licensed under the Creative Commons Attribution International License (CC BY).

http://creativecommons.org/licenses/by/4.0/

(c) $\underset{\mathrm{EY}}{\mathrm{O}}$ Open Access

\section{Abstract}

Purpose: To investigate whether long-term noise exposure affects the cognitive ability of grinders. Methods: Cumulative noise exposure (CNE) and $L_{A e q .8 h}$ determination were used to characterize the level of individual noise exposure; the Montreal Cognitive Assessment (MoCA) test (Beijing version) was used to evaluate cognitive function. Results: We compared the basic situation of workers in different groups and individual noise exposure intensity of grinders was monitored. Multiple linear-regression analysis was made and score of MoCA in different group was finally drawn. Conclusion: CNE and total score of MoCA have the relationship of negative correlation ( $r=$ $-0.303, p<0.05$ ) which means long-term occupational noise exposure can affect the cognitive ability of grinders.

\section{Keywords}

\section{Occupational Noise Exposure, Grinders, Cognitive Function, Montreal Cognitive Assessment}

\section{Introduction}

Occupational noise exposure is a worldwide problem, which has become one of the most influential occupational hazards. Every year, the occupational disease caused by occupational noise exposure in the new occupational disease ranking has been located in the top [1].

The impact of noise on human health is multifaceted. Long time working in noisy environment without protection can not only cause hearing loss, but also affect the human nervous system, cardiovascular system, digestive system and other adverse effects.

\footnotetext{
*Corresponding authors.
} 
Grinding is one of the main production processes of marine heavy industry enterprises. The grinders have the characteristics of high individual noise intensity, long contact time and large working number. At present, there are few reports on the impact of long-term occupational noise exposure on cognitive ability to grinders.

Xie Hong-Wei's research [2] [3] showed that there was dose-response relationship between cumulative noise exposure (CNE) and hearing loss. The change of cognitive ability can be used to judge the degree of damage caused by occupational hazard factors. As the typical work type suffered from occupational noise exposure, there were few research findings on cognitive ability of grinders. From the author's professional point of view, cumulative noise exposure (CNE) of grinders was one appropriate point for research subject. Therefore, we started from the CNE based on the level of individual noise exposure to understand the influence of occupational noise exposure on the cognitive ability of grinders.

\section{Object and Method}

\subsection{Object}

The marine heavy industry enterprises selected in this study was located in Qingdao, China, with the main products of ocean-going freighter and offshore platform. The enterprises had more than 1900 employees, moved to present site in 2005.

The number of the grinders was determined by the production order, provided by labor service company. During monitoring, there were nearly 1400 grinders working in the enterprises. The sample size was set by 10 percent of the grinders. In order to avoid the invalid data which may be produced during monitor process, we increased the sample size by $1 \%$, and finally determined the sample size of 155 .

According to "Law of the People's Republic of China on Prevention and Control of Occupational Diseases" and relevant laws and regulations, the employer shall have the factors of occupational disease hazards monitored and assessed regularly at the workplace. The author's unit was a service organization with Grade A qualification. Before carrying out this study, safety and environmental protection department of the enterprises has informed the monitored grinders, and obtained consent. This study didn't involve individual biological indicators, so it was not necessary to make ethical clearance.

The object of study was chosen by random sampling method with the help from safety and environmental protection department of the enterprises. 155 grinders were chosen as the exposure group. The exposure group consisted of 155 male grinders and 0 female grinder, average age was $(30.4+6.2)$ years old, average noise exposure seniority was $(6.2+4.7)$ years. The control group was composed of administrative personnel of the same enterprise. The control group usually worked in the administrative office, didn't contact with the factors of occupational disease hazards. The control group consisted of 104 male and 46 female, average age was (29.6 \pm 7.25) years old, average seniority was $(7.8 \pm 4.1)$ years. There was no significant difference in age, length of service between the exposure group and the control group ( $\mathrm{t}$ age $=1.118, \mathrm{P}>0.05$; t seniority $=0.095, \mathrm{P}>0.05$ ).

\subsection{Method}

The template is used to format your paper and style the text. All margins, column widths, line spaces, and text fonts are prescribed; please do not alter them. You may note peculiarities. For example, the head margin in this template measures proportionately more than is customary. This measurement and others are deliberate, using specifications that anticipate your paper as one part of the entire journals, and not as an independent document. Please do not revise any of the current designations.

- Investigation of general situation and cognitive ability.

- Investigation of general situation included personal basic situation and living habits such as smoking; Montreal cognitive assessment (MoCA) questionnaire was used for cognitive ability survey [4], which contained visual space/executive function, naming ability, attention, language ability, abstract ability, memory and orientation, the full mark was 5, 3, 6, 3, 2, 5, 6 respectively, the sum of 7 abilities was the total MoCA score.

- Determination of $\mathrm{L}_{\text {Aeq.8h }}$.

- QUEST noise pro personal noise dosimeter was applied for monitoring. According to "Measurement of Physical Agents in Workplace Part 8: Noise" (GBZ/T189.8-007), the frequency range was $20 \mathrm{~Hz}-8 \mathrm{kHz}$, detection interval 1second, detection time $8 \mathrm{~h}$, continuous detection of 3 classes. The grinders with $\mathrm{L}_{\text {Aeq.8h }}$ values greater than or equal to $80 \mathrm{~dB}(\mathrm{~A})$ were assigned to high exposure group; those less than $80 \mathrm{~dB}(\mathrm{~A})$ belong to the low exposure group. 
- Cumulative noise exposure (CNE).

- Based on the characteristics of grinding work, daily working hours of grinders were not fixed 8 hours. $\mathrm{L}_{\text {Aeq.8h }}$ values need to be converted according to actual working situation.

- The $\mathrm{L}_{\text {Aeq.8h }}$ and the grinders' noise exposure level were combined into the cumulative noise exposure, which was used to quantify the noise exposure of each study object [5].

$$
\mathrm{CNE}=10 \log \left(\frac{1}{T_{\text {ref }}} \sum_{i=1}^{n}\left(T_{i} \times 10^{L_{\text {Aeq }: 8 h i} / 10}\right)\right) .
$$

In this study, the workplace of all the study objects were relatively fixed, so formula (1) can be simplified into:

$$
\mathrm{CNE}=L_{\text {Aeq } 8 \mathrm{~h}}+10 \log T
$$

\subsection{Statistical Analysis}

EpiData 3.0 database was used for data entry, SPSS 16.0 software package was used for data statistical analysis. Single factor analysis was made on the relationship between the level of occupational noise exposure and cognitive ability. After controlling the covariates, we compared the differences in cognitive ability of different exposure groups, and then made the analysis on the factors which may affect workers' cognitive ability by multiple linear-regression analysis. The inspection level $\mathrm{a}=0.05$.

\section{Results}

\subsection{Monitoring Results of Individual Noise Exposure Intensity}

The time points of data collection was concentrated in June of each year, the exposure group and control group were detected simultaneously. The individual noise exposure intensity of grinders during 2013-2015 was respectively 86.8 - 90.8, 88.6 - 92.2, 87.8 - $91.9 \mathrm{~dB}(\mathrm{~A})$; the results of control group was 64.5 - 67.3, 63.7 - 68.2, 64.4 $67.8 \mathrm{~dB}(\mathrm{~A})$.

\subsection{Basic Situation of Workers}

Chi-square test was applied to compare the distribution of basic situation of the workers in different groups. The result showed that age, marital status were statistically significant $(\mathrm{P}<0.05)$, but cultural differences were not $(\mathrm{P}<0.05)$. Therefore, covariance analysis was applied to control the age, marital status and other factors on the cognitive ability of workers during the analysis procedure.

\subsection{Score of MoCA in Different Groups}

In this study, Chi-square test was applied to compare the distribution of basic situation of the workers in different groups to make sure the influence of the factors on the experimental indexes, such as the attention, the abstract ability, etc. By controlling the age, marital status and other factors, covariance analysis was applied on cognitive ability of 2 groups which was shown in Table 1 . The result showed that, the scores on visual space/ executive function, abstract ability, memory and orientation of exposure group were lower than control group (P < $0.05, \mathrm{P}<0.01$ ). There were no significant differences in the scores of other items among the groups.

\subsection{Multiple Linear-Regression Analysis on the Factors May Influence Cognitive Ability}

In order to avoid the possible interaction between the factors, multiple linear-regression analysis was applied to analyze the factors which may influence cognitive ability. MoCA total score was taken as the dependent variable; educational level, age, and others as independent variable.

The value of $\mathrm{P}$ entry model was evaluated 0.05 ; value of $\mathrm{P}$ of retention variable was evaluated 0.10 ; confidence level was 0.05 . Variables into the regression equation were shown in Table 2.

\section{Conclusion}

By making use of CNE up to 2015, Pearson single factor analysis was made to analyze the noise exposure level 
Table 1. Covariance analysis results of workers’ cognitive ability scores ( $\mathrm{x} \pm \mathrm{s})$.

\begin{tabular}{ccc}
\hline Variables & Control Group $(\mathrm{n}=150)$ & Exposure Group $(\mathrm{n}=155)$ \\
\hline Visual space/executive function & $3.762 \pm 0.068$ & $3.458 \pm 0.119^{*}$ \\
Naming ability & $2.766 \pm 0.033$ & $2.777 \pm 0.058$ \\
Attention & $5.465 \pm 0.052$ & $5.363 \pm 0.091$ \\
Language ability & $1.013 \pm 0.066$ & $1.006 \pm 0.098$ \\
Abstract ability & $1.199 \pm 0.051$ & $0.596 \pm 0.089^{* * \# \#}$ \\
Memory & $2.957 \pm 0.105$ & $2.478 \pm 0.184^{*}$ \\
Orientation & $5.823 \pm 0.037$ & $5.577 \pm 0.064^{* *}$ \\
Total MoCA score & $23.7 \pm 0.230$ & $21.7 \pm 0.400^{* *}$ \\
\hline
\end{tabular}

Note: compared with control group, $\mathrm{P}<0.05,{ }^{* *}$ : $\mathrm{P}<0.01$; ${ }^{\#}$ : compared with low exposure group, $\mathrm{P}<0.05,{ }^{\text {\#\# }}$ : $\mathrm{P}<0.01$.

Table 2. Multiple linear-regression analysis on total MoCA score among different noise exposure level.

\begin{tabular}{cccccc}
\hline Independent Variable & $\mathrm{b}$ & $\mathrm{Sb}$ & $\mathrm{t}$ & $\mathrm{P}$ & $95 \% \mathrm{CI}$ \\
\hline Constant term & 27.771 & - & 46.966 & $<0.001$ & $26.609-28.933$ \\
Educational level 1 & -1.106 & -0.132 & 2.072 & 0.039 & $-2.154--0.057$ \\
Educational level 2 & -0.146 & -0.019 & 0.311 & 0.756 & $-1.066--0.775$ \\
Age & -0.992 & -0.232 & 4.520 & $<0.001$ & $-1.423--0.560$ \\
CNE & -0.901 & 0.178 & 4.140 & $<0.001$ & $-1.329--0.473$ \\
\hline
\end{tabular}

of exposure group and the total score of MoCA, and we finally made the correlation analysis on CNE and total score of MoCA. The result showed that CNE and total score of MoCA had the relationship of negative correlation $(\mathrm{r}=-0.303, \mathrm{P}<0.05)$.

\section{Discussion}

Long-time occupational noise exposure will do harm to the health [6]. There is a close relationship between the incidence of noise induced deafness and seniority [7]. Moreover, the effect of noise on human health is varied [8].

This study was based on the statistical results of field investigation and detection. The causal relationship between occupational noise exposure and cognitive ability has not been established. The study period is from March 2013 to September 2105.

By this study, we found that CNE was negatively related to the cognitive abilities of workers $(\mathrm{P}<0.01)$, long-term occupational noise exposure may affect cognitive ability. After controlling the influence of covariant such as age, marital status, etc, the scores on visual space/executive function, abstract ability, memory, orientation and total MoCA score of exposure group were all lower than control group $(\mathrm{P}<0.05, \mathrm{P}<0.01)$; the scores on abstract ability and total MoCA score were also lower than control group $(\mathrm{P}<0.05, \mathrm{P}<0.01)$. During the procedure of multiple linear-regression analysis that may influence the cognitive ability of workers, different noise exposure level has a significant effect on the cognitive ability of workers, which showed high noise exposure levels and lower cognitive ability scores were correlated. Some research showed that language, learning and memory ability and other cognitive abilities of welders were lower than those of the control group [9].

Smoking status, age and educational level may have an impact on cognitive abilities besides exposure level during the procedure of multiple linear-regression analysis. FRIED found that cognitive ability of the smoking population was significantly lower than that of the non-smoking population [10]. Cohort study results by RICHARDS showed that cognitive ability decrease of the study population was positively correlated with daily smoking [11]. This research showed that scores of workers' cognitive ability decreased with the increase of smoking index, which was consistent with the previous studies. The results also showed that with the increase of age, the learning and memory ability of the workers gradually decreased; the higher the educational level, the 
higher the cognitive ability.

Occupational noise exposure can reduce the cognitive ability of grinders. What's more, smoking, age and educational level will have an impact on the cognitive ability. In this study, Montreal version of Beijing cognitive assessment scale was applied to evaluate grinders' cognitive ability. The next step will be taken to make the results more comprehensive with other cognitive assessment scales.

Due to production requirements, there will be operation at confined spaces in the process of subsection grinding. in summer. There might be combined effects of noise and high temperature. We will continue to explore the effect of the job category and the degree of harm on grinders.

\section{Acknowledgements}

This article was supported by National 11th Five-year Plan of Science and Technology Support Project (2006BAI06B02); Shandong Province Natural Science Fund Project (ZR2012HL08); Shandong Province Science and Technology Research Projects (2013GSF11828); Shandong Province Medical and Health Science and Technology Development Project (2014WS0337, 2015WS0171); Jinan Science and Technology Development Project (20130244, 201202045).

\section{References}

[1] Feng, H.-J. (2009) Analysis of Hearing Tests of 500 Workers Exposed to Noise. Occupand Health, 25, $1253-1254$.

[2] Xie, H.-W., Zhang, M.-B. and Quan, C.-J. (2014) A Study on Dose-Response Relationship between Cumulative Noise Exposure and Human Hearing Loss. Zhejiang Prev Med, 26, 340-344.

[3] Xie, H.-W., Zhang, M.-B., Zhang, L., et al. (2013) Measurement and Evaluation on Workplace Non-Steady Noise Exposure. Journal of Environmental \& Occupational Medicine, 30, 748-752.

[4] Jiang, L. (2008) Analysis of Blood Pressure Check Results of Noise Exposed Workers. Safety Health \& Environment, 12, 40.

[5] Zhao, Y.-M. and Cheng, M.-K. (1998) Advances in the Study of Cumulative Noise Exposure. Chinese Journal of Occupational Health and Occupational Diseases, 16, 123-124.

[6] Hao, Z.-P. (2009) Research on Human Health Hazards of Industrial Noise. Shanxi Med, 38, 1080

[7] Guo, Y., Han, S.-Q. and XU, Y.-H. (2012) Investigation on Association of Occupational Noise Exposure, Duration of Work and Cumulative Noise Exposure with Hearing Loss in Textile Mill Workers. China Modern Medicine, 19, 50154.

[8] Liu, F. and Jiang, J. (2008) Analysis of ECG Examination Results in Noise Workers. China Practical Medical, 28, 196-197.

[9] Bowler, R.M., Gysens, S., Diamond, E., et al. (2006) Manganese Exposure: Neuropsychological and Neurological Symptoms and Effects in Welders. Neuro Toxicology, 27, 315-326. http://dx.doi.org/10.1016/j.neuro.2005.10.007

[10] Fried, P.A., Watkinson, B. and Gray, R. (2006) Neurocognitive Consequences of Cigarette Smoking in Young Adults-A Comparison with Pre-Drug Performance. Neurotoxicology and Teratology, 28, 517-525. http://dx.doi.org/10.1016/j.ntt.2006.06.003

[11] Richards, M., Jarvis, M.J., Thompson, N., et al. (2003) Cigarette Smoking and Cognitive Decline in Midlife: Evidence from a Prospective Birth Cohort Study. American Journal of Public Health, 93, 994-998.

http://dx.doi.org/10.2105/AJPH.93.6.994 


\section{Submit or recommend next manuscript to SCIRP and we will provide best service for you:}

Accepting pre-submission inquiries through Email, Facebook, LinkedIn, Twitter, etc.

A wide selection of journals (inclusive of 9 subjects, more than 200 journals)

Providing 24-hour high-quality service

User-friendly online submission system

Fair and swift peer-review system

Efficient typesetting and proofreading procedure

Display of the result of downloads and visits, as well as the number of cited articles

Maximum dissemination of your research work

Submit your manuscript at: http://papersubmission.scirp.org/ 